\title{
As mudanças habitacionais em regiões metropolitanas brasileiras
}

\author{
Housing changes in Brazilian metropolitan areas
}

César Marques ${ }^{[0]}$, Henrique Frey ${ }^{[b]}$

[a] Escola Nacional de Ciências Estatísticas (ENCE), Rio de Janeiro, RJ, Brasil

[b] Faculdade Pitágoras, Votorantim, SP, Brasil

\section{Resumo}

A partir da década de 2000, o mercado de habitação brasileiro passou por sensíveis mudanças, que permitiram a retomada do crescimento da construção civil, do número de unidades construídas e comercializadas. Tais mudanças foram possíveis em função de uma série de mudanças nas políticas urbanas e habitacionais, com destaque para a ampliação da oferta do financiamento habitacional, que permitiu a incorporação de uma parcela maior da população no acesso à casa própria. No entanto, os efeitos das recentes políticas de habitação ainda não são claros. Por um lado, o crescimento do valor dos bens imobiliários foi generalizado, alcançando patamares comparáveis a de importantes centros mundiais, principalmente nas grandes cidades e metrópoles brasileiras. Por outro, ainda pouco se sabe sobre os efeitos quantitativos desse modelo, ou seja, se de fato a parcela da população com acesso ao domicílio próprio aumentou significativamente e houve uma consequente queda do número de domicílios alugados e cedidos. Para isso, esse artigo propõe uma primeira análise exploratória, utilizando os dados dos Censos Demográficos 1991, 2000 e 2010 para avaliar se tais políticas alteraram as dinâmicas das condições de ocupação nos domicílios na escala metropolitana. Analisamos dados das três maiores regiões metropolitanas (Belo Horizonte, São Paulo e Rio de Janeiro) a partir do município, comparando as mudanças na sede e no entorno. 0 texto está estruturado em torno da discussão do mercado habitacional no Brasil, das inovações em termos de políticas públicas no período recente e da própria análise dos dados censitários, apontando suas potencialidades e limites.

Palavras-chave: Urbanização. Dinâmica imobiliária. Políticas públicas de habitação.

\section{Abstract}

From the 2000s, the Brazilian housing market has undergone significant changes that allowed the resumption of construction growth, the number of units built and sold. These changes were made possible due to a number of changes in urban and housing policies, especially in the expansion of the supply of housing finance, allowing the incorporation of a larger portion of the population in access to housing. However, the effects of these recent

CM é Sociólogo, doutor em Demografia, e-mail: cesar.m.silva@ibge.gov.br

HF é Sociólogo, mestre e doutorando em Demografia, e-mail: henriquefrey@yahoo.com.br

urbe. Revista Brasileira de Gestão Urbana (Brazilian Journal of Urban Management), 2015 maio/ago., 7(2), 250-267 
housing policies are not clear yet. On the one hand, the growth in the value of real estate was widespread, reaching levels comparable to the major worldwide centers, especially in large Brazilian cities and metropolitan areas. On the other hand, there is little knowledge about the quantitative effects of this model. That means that it is still unknown whether the share of homeowners has increased significantly, with a consequent reduction in the number of rented homes. To this end, this article proposes an initial exploratory analysis using data from the 1991, 2000 and 2010 Demographic Censuses. The objective is to assess whether these policies have altered the dynamics of occupation conditions in households in the metropolitan scale. We analyzed data from the three largest metropolitan areas (Belo Horizonte, Sao Paulo and Rio de Janeiro) in the country, comparing the changes between central and peripheral cities. The text is structured on the discussion of the housing market in Brazil, including the innovations in terms of public policies in recent period and on our own analysis of census data, indicating their potential and limits to deal with housing issues.

Keywords: Urbanization. Housing dynamics. Public housing policy.

\section{Introdução}

Como direito, a moradia digna é assegurada no Brasil pelo artigo $6^{\circ}$ da Constituição Federal de 1988 (Brasil, 1988). É um direito fundamental, cabendo ao Estado a promoção das condições necessárias para sua efetivação. Essa realidade vai muito além da discussão brasileira, sendo a moradia já consolidada como uma questão de dignidade humana, consagrada como constituinte dos direitos humanos no âmbito internacional.

Contudo, essa efetivação é controversa no Brasil. Sua urbanização acelerada, desacompanhada de uma planificação real das políticas urbanas e de habitação, levam à ausência de moradia digna para grande parte dos brasileiros. As principais medidas dessa realidade são expressas através do déficit e da demanda habitacional. 0 primeiro indica a falta de moradias para pessoas ou famílias que necessitam de habitação, relacionado à falta física da unidade habitacional no estoque disponível no mercado. Já a demanda é a necessidade de um grupo populacional específico por um tipo de "bem habitação" dotado de características específicas (CEF, 2011). Em termos sociais, é o déficit habitacional o tema mais preocupante: ele está relacionado às carências de determinados grupos sociais, seja pela falta de moradia, seja pela ausência de condições adequadas de habitações, sendo dado pelo resultado entre a subtração da demanda pela oferta de bens com caráter social (Garcia \& Castelo, 2006). No entanto tais conceitos são polissêmicos e não consensuais.
O principal financiador imobiliário do Brasil, a Caixa Econômica Federal (CEF), calcula a demanda por moradias a partir de elementos demográficos e habitacionais. Os quesitos demográficos utilizados no índice são: ciclo de vida e transição para a vida adulta; padrões de conjugalidade e idade média ao casar; a formação de novos arranjos domiciliares e a distribuição das taxas de chefia (CEF, 2011). A partir da inclusão desses três elementos, calculam-se projeções com a chamada Demanda Habitacional Demográfica (DHDE), que é uma demanda potencial. Complementarmente, também se calcula a Demanda Habitacional Domiciliar (DHDO), obtida por meio do levantamento do número de moradias inadequadas, que possuem uma das três características: domicílios improvisados, casas de cômodos ou domicílios sem banheiro ou vaso sanitário. Somadas, obtém-se a Demanda Habitacional Total (DHT). A Tabela 1 indica os resultados para o período 2001-2009, calculados a partir de dados da PNAD.

Desse cálculo, ao menos uma grande conclusão pode ser obtida: o peso relativo da demanda habitacional caiu, não pela queda absoluta da demanda, mas sim pelo aumento absoluto do número total de moradias. Isso significa, que dentre as novas construções, é crescente o número de moradias adequadas, no entanto, que há um residual importante de moradias inadequadas com número relativamente estável. Embora tenhamos verificado uma variação no período coberto pela análise, o total de domicílios demandados ficou praticamente igual, em 9,3 milhões.

A Fundação João Pinheiro (FJP) também elabora anualmente levantamentos do déficit habitacional 
Tabela 1 - Evolução da Demanda Habitacional 2001-2009

\begin{tabular}{cccccc}
\hline Ano & Total de domicilios & DHDE & DHDO & DHT & DHT/Total de domicilios \\
\hline 2001 & 46.994 .866 & 5.441 .662 & 3.845 .659 & 9.287 .321 & $19,76 \%$ \\
2002 & 48.095 .210 & 5.562 .830 & 3.498 .303 & 9.061 .133 & $18,84 \%$ \\
2003 & 49.729 .167 & 5.746 .217 & 3.247 .523 & 8.993 .740 & $18,09 \%$ \\
2004 & 51.666 .039 & 6.043 .317 & 3.151 .322 & 9.194 .639 & $17,80 \%$ \\
2005 & 52.910 .174 & 6.199 .923 & 3.029 .404 & 9.229 .327 & $17,44 \%$ \\
2006 & 54.282 .533 & 6.430 .460 & 2.839 .964 & 9.270 .424 & $17,08 \%$ \\
2007 & 55.877 .855 & 6.681 .275 & 2.767 .152 & 9.448 .427 & $16,91 \%$ \\
2008 & 57.656 .117 & 6.746 .274 & 2.478 .686 & 9.224 .960 & $16,00 \%$ \\
2009 & 58.646 .432 & 6.978 .415 & 2.318 .799 & 9.297 .214 & $15,85 \%$ \\
\hline
\end{tabular}

Fonte: Adaptado de CEF (2011), elaborado a partir de PNAD (2001 a 2009), IBGE Dados Reponderados e Estudo Demanda Habitacional 2009.

no Brasil, que são incorporados pelo Ministério das Cidades. A publicação, feita desde 1995, estima o déficit habitacional e a inadequação dos domicílios. Na primeira se indica a necessidade de construção de novas moradias; a segunda está relacionada ao dimensionamento das moradias inadequadas, que prejudicam a qualidade de vida dos moradores. Ao longo dos anos, a metodologia do documento foi desenvolvida (destacamos a incorporação do tema da coabitação familiar no ano de 2007) e se consolidou como importante documento no planejamento habitacional brasileiro (Brasil, 2011).

Para 2008, a FJP estima um déficit habitacional de 5,55 milhões de domicílios, o que equivale a $9,6 \%$ do total de domicílios no Brasil, dos quais aproximadamente $36,9 \%$ estão concentrados na região Sudeste e $35,1 \%$ no Nordeste. No Sudeste, $96,3 \%$ do déficit se concentra nas áreas urbanas.

Embora os documentos apresentem resultados bastante díspares quanto aos números totais, com conceitos e metodologias distintas, algumas conclusões são bastante similares: as maiores carências de moradia estão concentradas nas menores faixas de renda, há maior demanda por construções no Sudeste e Nordeste e relativamente o déficit habitacional está decrescendo.

No entanto, sobre quais condições essas dinâmicas se efetivam? Que tipo de urbanização ocorre no Brasil e na América Latina como um todo? 0 relatório ONU-Habitat (2010) indica que nas áreas urbanas do continente houve lenta melhoria das condições das cidades. Essas são cada vez mais desiguais, apresentam demanda crescente por políticas de redução da pobreza urbana, com condições ambientais degradadas e continuidade de problemas tipicamente urbanos: transporte público de má qualidade, ausência de habitações populares a preços acessíveis, expansão de favelas com ausência de urbanização adequada e fraca expansão de serviços de infraestrutura. Se nas cidades há também condições que permitem a melhoria de vários indicadores (longevidade, educação, saúde, por exemplo), nessas áreas do continente e do Brasil ainda segue uma situação de desigualdade que privilegia poucos.

Nesse quadro geral, o presente trabalho busca avaliar quais os impactos da política habitacional brasileira nas três maiores Regiões Metropolitanas (RMs) do Sudeste: Belo Horizonte, Rio de Janeiro e São Paulo, com o intuito de analisar a evolução das formas de habitar nas últimas duas décadas, entre 1991 e 2010. Nosso objetivo não é construir mais um índice de demanda e déficit habitacional, mas sim analisar quais as condições de ocupação dos domicílios nesse período. Partimos dessa questão para avaliar os impactos das políticas de habitação nessas três regiões metropolitanas, a partir dos dados dos Censos Demográficos realizados no período. De modo direto, não estimamos as demandas, mas avalia-se o resultado do processo de urbanização no tocante à moradia.

Dois objetivos específicos são colocados: analisar as potencialidades e limites do Censo Demográfico para avaliar políticas públicas de habitação e avaliar algumas das consequências da forma de habitação na metrópole, principalmente em relação à mobilidade espacial da população, em sua dimensão cotidiana, 
referente aos deslocamentos necessários à reprodução da vida e do trabalho.

Nossa hipótese básica é a de que, embora o número de residências construídas via financiamento habitacional tenha crescido grandemente nos últimos anos e as estimativas de déficit habitacional mostrem um relativo controle da situação, tal política tem beneficiado muito mais a especulação imobiliária e os grupos populacionais com maior renda, que podem adquirir um ou mais imóveis em localizações específicas, onde o preço do solo é bastante elevado. Também se levanta a hipótese de que, nas regiões metropolitanas, o impacto das políticas habitacionais é mais intenso nos municípios do entorno metropolitano e menos na sede. Isso porque a elevação do preço do solo nos centros praticamente inviabiliza empreendimentos com custo menor, que atenda à maior parte do déficit habitacional. Para isso, serão analisados os dados a partir de três conjuntos de delimitações espaciais: da região metropolitana como um todo, da sua sede e do entorno.

Ainda ressaltamos que, de modo geral, nossa preocupação não será com o desempenho do mercado imobiliário, mas sim com as possibilidades de moradia que se formaram na última década. Assim, não utilizamos o termo imóveis, mas sim domicílios, já que nossa preocupação está na casa, residência, lugar essencial para a afirmação de sentido e construção da trajetória de vida pessoal.

\section{O mercado de habitação no Brasil}

O dualismo da habitação enquanto mercado e direito humano fundamental caracteriza uma situação bastante peculiar. Para compreendê-la é preciso ter a visão das transformações mais amplas da dinâmica do capital e refletir sobre os impactos profundos para sua efetivação como direito humano.

Assim, se na contemporaneidade os financiamentos habitacionais se configuram como um tema essencial nas possibilidades de obtenção de moradia digna, é necessário relacionar os padrões de financiamento da política habitacional às transformações dos padrões da acumulação capitalista. Conforme Royer (2009) aponta, a expansão material do sistema capitalista durante o século XX nos países desenvolvidos permitiu que o Estado fosse fonte central no financiamento habitacional. Tais Estados, baseados no modelo do Bem-estar Social, incorporam o acesso à moradia nos custos da reprodução da força de trabalho, atribuindo salários de modo indireto e configurando uma situação em que a questão era enfrentada pela esfera pública. No entanto, a expansão financeira mundial, a crise fiscal e a insuficiência de fundos geridos pelo Estado esvaziaram a sustentação do modelo de bem-estar social, colocando no mercado funções por ele antes cobertas.

Kowarick (1993) traz ponderações fundamentais sobre essa dinâmica. Através da reflexão sobre a relação mercado de trabalho e expansão urbana, o autor debate o contexto da cidade São Paulo, colocando-a como um caso central à questão urbana em âmbito nacional. Reconstituída em termos históricos, essa urbanização se deu, até a década de 1930, basicamente pela construção de vilas operárias associadas à atividade industrial. Com baixos custos de terrenos, as indústrias se responsabilizavam pela construção das moradias, o que também lhes permitia o pagamento de salários menores e a fixação mais rápida dos trabalhadores. Com a intensificação da industrialização, a pressão sob moradias populares também aumentou. $\mathrm{Na}$ medida em que se gerava um excedente da força de trabalho, as indústrias passaram para o trabalhador a busca do habitar e, consequentemente, os gastos com o transporte. 0 mercado imobiliário passou a imperar sob as relações econômicas do solo urbano, restringindo o acesso de uma parcela da população. A periferia, na acepção sociológica do termo, surge nesse contexto.

Nesse cenário houve a primeira iniciativa brasileira para a criação de uma política habitacional com abrangência nacional, a partir da Lei n. ${ }^{\circ} 4.380 / 64$. Foram instituídos o Sistema Financeiro de Habitação (SFH) e o Banco Nacional de Habitação (BNH), centrais à formulação da política nacional de habitação, com o Governo Federal atuando como responsável pela coordenação de ações públicas e privadas na construção e financiamento das residências. Teoricamente, a iniciativa visou atender às demandas das famílias de baixa e média renda (Morais, 2002; Köhler, 2005; CEF, 2011).

0 recém-instituído governo militar procurava um duplo objetivo: resolver a questão habitacional e combater os progressistas. Nos seus primeiros cinco anos de existência foram construídas 178.227 unidades habitacionais, com $40,7 \%$ dos recursos destinados a famílias de baixa renda. A partir da década de 1970, os recursos foram redirecionados para a classe média, 
considerada mais rentável pelos financiadores. Enquanto nesse nicho as taxas de juros giravam em torno de $10 \%$ ao ano, para as classes de menor renda os juros variavam de 1 a 3\% (Yoshimura, 2004; Fernandes \& Silveira, 2010).

Mesmo com as críticas, o BNH e o sistema por ele preconizado são considerados como o período de mais ampla e eficaz política de habitação (1964-86). Os resultados, do ponto de vista quantitativo, foram expressivos: 4,3 milhões de unidades novas, com 2,4 milhões destinadas ao setor popular com recursos do FGTS e 1,9 milhão com recursos do SBPE a residências da classe média. Considerando o período posterior, até o ano de 2000 (com o SFH ainda em funcionamento) foram financiadas cerca de 6,5 milhões de unidades habitacionais. Ademais, o SFH também teve papel central na construção de infraestrutura (como no sistema de saneamento) (Bonduki, 2008).

A crise econômica dos anos 1970 e a intensa urbanização brasileira do período apresentaram desafios que o BNH não foi capaz de equacionar. 0 aumento da inflação, do desemprego e a queda dos níveis salariais geraram desequilíbrios sucessivos no SFH, dadas as alterações nas regras de correção monetária.

Em relação à urbanização, entre 1950 e 2000, a população em cidades com mais de 20 mil habitantes cresceu de 11 milhões para 125 milhões (Bonduki, 2008). $\mathrm{O}$ volume absoluto de residências a construir que $\mathrm{o}$ BNH deveria ser capaz de estimular era imenso e, de fato, esse não foi capaz de fazê-lo. Ao voltar-se mais para o beneficiamento da construção civil, a política adotada ofereceu ao setor uma fonte de financiamento estável à construção de habitações prontas e deixou de apoiar a construção de moradias e uma urbanização que incorporasse o esforço e a capacidade das próprias comunidades, pouco contribuindo para enfrentar de fato o problema ao qual se propunha resolver (Bonduki, 2008).

Em 1986, com o decreto-lei 2.291/86, foi extinto o BNH (Brasil, 1986). A Caixa Econômica Federal assumiu a administração do passivo, do ativo, do pessoal, dos bens do BNH e a operação do FGTS, adquirindo a condição de principal executor das políticas habitacionais do Governo Federal (CEF, 2011). 0 fim do regime militar em 1985, e do BNH em 1986, trouxe um longo período de ausência na política habitacional com abrangência nacional, que vai até a criação do Ministério das Cidades, em 2003. Nesse período, a
CEF assumiu o papel de agente financeiro do SFH e o Conselho Monetário Nacional regulamentou o crédito habitacional, tornando-o de fato um instrumento de política monetária (Bonduki, 2008).

Em meio a crises políticas, econômicas, deterioração das condições de vida e empobrecimento da população, as décadas de 1980 e 1990 foram um palco de iniciativas limitadas e não integradas no campo urbano e habitacional. Para Bonduki (2008), esse foi um período de transição, com Estados e municípios buscando fontes alternativas para os financiamentos e execução das construções. É importante mencionar que este rearranjo institucional na orientação das políticas de Habitação passou, também, pelas prerrogativas de descentralização expressos na Carta de 1988, com ampliação do poder local (Carvalho, 2011). As iniciativas foram diversas e surgiu um conjunto de ações voltadas a habitações de interesse social. Programas alternativos, como a urbanização de favelas e assentamentos precários, construção via mutirões, apoio à autoconstrução e intervenções em cortiços e residências em áreas centrais, foram implementadas a partir de ações localizadas.

Como política nacional do período, destacam-se iniciativas como o programa Habitar-Brasil e Morar-Melhor, com recursos oriundos do Orçamento Geral da União (OGU) e do Imposto Provisório sobre Movimentações Financeiras (IPMF). 0 resultado, porém, foi aquém do esperado, dado o contingenciamento de recursos do Plano Real.

A questão habitacional entrou no século XXI como não resolvida. Houve piora do déficit habitacional entre 1991 e 2000 e aumento de sua concentração nas famílias com menores níveis de renda. Entre 1995 e $2003,78,84 \%$ do total dos recursos de financiamentos foram alocados a famílias com renda superior a 5 salários mínimos, e apenas $8,47 \%$ a famílias com renda de até 3 salários mínimos. Em 2000, 83,2\% do déficit estava concentrado nas famílias com rendas de até 3 salários mínimos (Bonduki, 2008).

Assim, dois movimentos foram fundamentais no início da década de 2000: a aprovação do Estatuto das Cidades em 2001, criando instrumentos importantes para o desenvolvimento urbano, como o plano diretor; e a criação do Ministério das Cidades, em 2003, com a função de coordenar, gerir e formular a Política Nacional de Desenvolvimento Urbano (Fernandes \& Silveira, 2010). 
No entanto, os recursos voltados para a habitação e as operações de financiamento continuaram centrados na CEF, instituição subordinada ao Ministério da Fazenda. A atuação do Ministério das Cidades foi limitada, com um poder de financiamentos e gestão de projetos centrados no próprio banco, a critério da CEF (Bonduki, 2008).

Nesse momento, a estrutura habitacional foi composta por uma nova Política Nacional de Habitação (PNH), com um Sistema Nacional de Habitação (SNH), e um Plano Nacional de Habitação (PlanHab). Tais mudanças incorporaram de forma mais incisiva, novamente, a Habitação de Interesse Social (HIS). Dentro dessa perspectiva, os mecanismos para obtenção de residências próprias cresceram e foram novamente incentivados, com destaque para a implantação do Sistema Nacional de Habitação de Interesse Social (SNHIS), composto pelo Fundo Nacional de Habitação de Interesse Social (FNHIS), pelos programas gestados pelos recursos do Orçamento Geral da União (OGU), pelo FGTS, através do Fundo de Arrendamento Residencial (FAR) e Fundo de Desenvolvimento Social (FDS); e pelo Programa Minha Casa, Minha Vida (PMCMV) (Fernandes \& Silveira, 2010).

Dentre tais iniciativas, certamente a de maior destaque é o PMCMV. Voltado a famílias com até 10 salários mínimos, oferecendo subsídio integral às famílias com renda de até 3 salários mínimos (SMs) e subsídio parcial àqueles com renda entre 3 e 10 SMs, o programa busca compatibilizar a prestação da casa própria com a capacidade de pagamento da família. Ao todo, espera-se um investimento de aproximadamente 34 bilhões de reais no programa.

No entanto, o efeito de tais iniciativas será de fato o desejado? Em que localização da cidade tais empreendimentos serão feitos? Serão suficientes para ao menos a minimização do problema? Envolvidos em um mercado imobiliário altamente especulativo, é necessário pensar também nos efeitos indiretos de tal política. Tais efeitos ocorrem em uma economia globalizada, altamente influenciada pelos movimentos da financeirização internacional. A recente crise financeira de 2008, por exemplo, atingiu o mercado global de forma generalizada e o mercado habitacional de forma bastante específica. Um desses efeitos está na criação de bolhas imobiliárias, sendo o Brasil um dos países emergentes que faz parte da lista dos que podem ser afetados por tais processos (Cuaresma, 2010).

D'Agostini (2010) defende que é possível vislumbrar o crescimento da bolha imobiliária no Brasil dados alguns elementos, dentre os quais destacamos: (i) a forte expansão do crédito sobre o Produto Interno Bruto (PIB), (ii) a expansão do endividamento das famílias em relação a seus salários; (iii) menor ritmo de crescimento da massa salarial na última década, em relação ao ritmo de crescimento dos preços dos imóveis e/ou do indicadores de evolução de preços do setor imobiliário; (iv) ingresso de capitais especulativos oriundos da arbitragem das taxas de juros; (v) carência de uma reforma tributária; e (vi) o alto crescimento do PIB brasileiro de 2010, que não se sustenta nos anos posteriores.

Em Curitiba, por exemplo, a disparada dos preços dos imóveis ocorreu a partir de outubro de 2007. Até então, os preços médios relativos à venda de apartamentos novos era relativamente estável, abaixo de $\mathrm{R} \$ 1.500,00$ o $\mathrm{m}^{2}$. Em 2010, os preços médios foram superiores a $\mathrm{R} \$ 3.000,00 / \mathrm{m}^{2}$ para apartamentos de 1 e 4 dormitórios, e de aproximadamente $\mathrm{R} \$ 2.500,00$ para unidades de 2 e 3 dormitórios. Em 4 anos (entre 2007 e 2010), o aumento no preço médio de apartamentos novos de 1 quarto foi de 130\% na cidade (Dezordi, 2012).

Em São Paulo, foi clara a retomada do fôlego do mercado imobiliário. Até 2003, as unidades residenciais novas não superavam 15 mil unidades/ano. Em 2004, esse número superou os 15 mil, e em 2007 foi superior a 35 mil (Alcântara, 2009). Segundo o índice FipeZap, calculado pela Fundação Instituto de Pesquisas Econômicas (Fipe) e o site Zap Imóveis, dos jornais $O$ Estado de S.Paulo e $O$ Globo, na capital paulista a valorização imobiliária foi de $86,9 \%$ em apenas 36 meses, tendo como base o mês de junho de $2012^{1}$.

\section{A urbanização brasileira e as formas de habitar}

As discussões que envolvem a problemática urbana, suas características e implicações, morfologias e desdobramentos, seja do ponto de vista social, econômico, político ou demográfico, ainda demarcam suas características de caos e desordem. Destacam-se o acesso desigual a bens e serviços, o tipo de ocupação e uso do solo em determinadas áreas, as possibilidades (e restrições) relativas à mobilidade urbana, dentre outras. Cumpre dizer que, na perspectiva metropolitana, estas questões ganham ainda mais amplitude (Maricato, 2011). Trata-se de um cenário complexo,

\footnotetext{
$\overline{{ }^{1} \text { Recuperado em } 9}$ de julho de 2012, de site http://www. zap.com.br/imoveis/fipe-zap/
} 
com desafios que se apresentam cotidianamente às pessoas que habitam as cidades. E, de acordo com os dados do Censo Demográfico de 2010, este é o local de residência de $84,4 \%$ da população brasileira.

Observado historicamente, verifica-se que o processo de urbanização brasileiro está alicerçado na dinâmica de inserção gradual da economia nos moldes capitalistas, com a formação de uma sociedade urbano-industrial espacialmente concentrada no centro-sul do país. Sua expansão urbana ocorreu com uma maciça migração rural-urbana, em meio ao crescimento populacional intenso dado pela transição demográfica (queda da mortalidade com posterior queda da fecundidade), como descrevem Martine \& Camargo (1984). É importante destacar que esses fluxos eram compostos de trabalhadores ligados, em sua maioria, à atividade agrícola de subsistência que fariam parte do excedente de mão de obra nas cidades (Singer, 1974).

Faria (1991) sintetiza que as mudanças verificadas no Brasil têm como principais aspectos: o ritmo da progressão - a taxa de urbanização quase dobra num curto período, passando de $36 \%$ em 1950 para $68 \%$ em 1980; a conformação de um sistema de cidades; a dinâmica do emprego e da estrutura ocupacional das cidades com forte expansão do setor de bens de consumo duráveis; a distribuição da renda e ampliação do consumo com ênfase para a política de crédito ao consumidor; e o acesso desigual aos serviços e equipamentos de consumo coletivo.

Os dados do Censo Demográfico 2010 mostram que $45 \%$ dos domicílios particulares permanentes estão distribuídos nas 36 regiões metropolitanas, onde reside pouco mais da metade da população brasileira. Esse processo de concentração populacional é mais evidente se consideradas apenas as Regiões Metropolitanas (RMs) de São Paulo, Rio de Janeiro e Belo Horizonte, onde residem 36,5 milhões de pessoas (pouco menos de um quarto da população urbana do Brasil).

A literatura referente à expansão urbana destaca o processo de periferização como um dos produtos da consolidação das metrópoles (que pressupõe concentração econômica e populacional numa determinada área) (Kowarick, 1993; Maricato, 1979; Bonduki \& Rolnik, 1978). 0 maior crescimento dos municípios localizados no entorno do município-sede, como no caso de São Paulo, seria a expressão das desigualdades sociais e econômicas dadas pela segregação espacial das camadas mais pobres da sociedade. Nesses termos, a periferia exprime as relações inerentes à lógica de reprodução capitalista. Destarte as diversas implicações que envolvem esta temática, as questões referentes à moradia ocupam papel central.

Tendo em vista a urgência e importância da discussão em torno do acesso não apenas à moradia digna, mas à cidade (Rolnik \& Klink, 2011), é que o presente artigo analisa como participam os diferentes atores envolvidos na dinâmica de obtenção da casa a partir das políticas públicas de habitação nas últimas décadas, com ênfase neste último decênio.

Os enfrentamentos da questão ao longo do tempo quase que se restringem ao sistema de financiamento da moradia que não se deram de maneira satisfatória. Algumas das razões de uma política habitacional pouco exitosa ao longo do tempo também são compartilhadas por outros países latino-americanos e caribenhos, como México, Colômbia, Argentina e Peru, que juntos com o Brasil concentram a maior parte do déficit habitacional da região. Segundo a Cepal (2006), as causas comuns, que implicam na reprodução desta situação são: "[...] gasto social en vivienda demasiado bajo; políticas de vivienda que no han sido eficientes; falta o escasez de esquemas de financiamiento; $y / o$ derechos de propiedad sobre la tierra y la vivienda muy ambíguos [...]" (Cepal, 2006, p. 6).

No referido documento, destacam-se ainda i) a queda da evolução dos gastos sociais por setores específicos a partir do Produto Interno Bruto, que, no setor da habitação, passou de 1,2\% em 1990 para 0,9\% do PIB em 2003; ii) experiências promissoras baseadas principalmente em fontes de subsídios para aquisição da moradia à população mais pobre e iii) os obstáculos que se apresentam na implementação desta ação (Cepal, 2006).

Comparando as políticas habitacionais em outros países ${ }^{2}$ e as semelhanças ou diferenças com relação ao caso brasileiro, é preciso atentar particularmente para o papel do Estado. Na Europa e Estados Unidos, a percepção dos reformadores sociais sobre a profunda miséria dos pobres urbanos do final do século XIX levou os governos ao envolvimento na provisão de moradias (Bratt et al., 2006). Tanto nos EUA, logo após a "Grande Depressão", quanto nos países europeus, sobretudo no período pós-Segunda Guerra, mantêm-se políticas

\footnotetext{
2 Para os países da União Europeia, ver: Czischke \& Pittin (2007).
} 
que provinham habitação de interesse social, até que este modelo passa a ser questionado (Dodson, 2006).

De acordo com Rolnik (2009), trata-se da efetivação das políticas com prerrogativas neoliberais em que se verifica a mudança do papel do Estado. Nesta conjuntura, em que se percebem a participação diminuta do Estado e as ações orientadas para o mercado, como pensar no provimento de moradia digna e de interesse social? A entrada contundente dos mercados financeiros na questão habitacional marca esse processo em que o acesso à casa como direito depende da condição econômica do indivíduo. Nesses termos, uma política habitacional ancorada na dinâmica do sistema financeiro, além de distanciar o cidadão da moradia digna, traz consequências às cidades como um todo. Para Rolnik \& Klink (2011):

num sistema de acumulação que não reproduz os custos da força de trabalho, e com um Estado que apresenta capacidade de investimento em urbanização limitada e quase inexistente regulação do mercado imobiliário e da terra urbana, o mercado não acompanha o crescimento econômico da cidade, produzindo cidades sem urbanidade. (Rolnik \& Klink, 2011, p. 101-102).

Ainda é importante mencionar os efeitos da ação desse tipo de diretriz no provimento de moradia. Sob o título "A atual crise habitacional, financeira e econômica", o relatório elaborado por Rolnik (2009) para a $\mathrm{ONU}^{3}$ apresenta a relação entre estas esferas, enfatizando os problemas relativos à manutenção de um modelo baseado no negócio hipotecário de alto risco (subprime), ao mesmo tempo em que indica a necessidade de avaliar o impacto da crise sobre o direito à moradia adequada. A relatora salienta ainda que a crise e suas origens no mercado habitacional são reflexos de falhas das atuais políticas econômicas e habitacionais, que revelam a incapacidade do mercado em prover moradia adequada e financeiramente acessível.

\section{Análise dos dados demográficos: resultados}

Dentre as várias inovações metodológicas e do questionário implementadas pelo Censo Demográfico de 2010, duas delas são de particular interesse neste

\footnotetext{
3 Raquel Rolnik foi relatora especial da Organização das Nações Unidas (ONU) para o direito à moradia entre 20082011 e 2011-2014.
}

artigo. Com ele, pela primeira vez é possível comparar, em períodos diferentes, os domicílios próprios considerando os já quitados e os ainda em pagamento, ou seja, criar uma proxy da realização dos financiamentos a partir de dados censitários. Considerando a implementação das políticas habitacionais recentes, inclusive com o estímulo ao instrumento do Sistema Financeiro de Habitação (SFH), poder-se-ia esperar uma retomada do crescimento dos domicílios com essa forma de ocupação. Calculamos tais dinâmicas na Tabela 2, mostrando dados relativos a três censos demográficos (1991, 2000 e 2010) e três regiões metropolitanas (Belo Horizonte, Rio de Janeiro e São Paulo). Em 1991, as variáveis do Censo permitiram a divisão segundo as seguintes condições de ocupação: Domicílios próprios, alugados, cedidos e em outra condição. Para 2000 e 2010, foi possível separar os domicílios próprios em duas categorias: já quitados e ainda em pagamento. Para todos os períodos também constam os valores totais dos domicílios. Com tais dados também foram calculadas as taxas de crescimento de cada uma das condições de ocupação, que estarão mapeadas para a melhor compreensão da dinâmica espacial das formas de habitar. Além disso, também computamos os dados do crescimento populacional e dos domicílios na Tabela 3.

Genericamente, as dinâmicas ressaltadas na análise da Tabela 2 e 3 são:

i. Como um todo, nas regiões metropolitanas do estudo houve aumento da participação dos domicílios próprios entre 1991 e 2000, com estabilidade entre 2000 e 2010;

ii. As taxas de crescimento dos domicílios sempre foram superiores às taxas de crescimento da população;

iii. As porcentagens de domicílios alugados, que haviam caído entre 1991 e 2000, voltaram a subir no período posterior;

iv. 0 crescimento do entorno sempre foi relativamente superior ao crescimento da sede;

v. Os domicílios financiados e ainda não pagos tiveram crescimento absoluto negativo tanto na sede como no entorno na RMRJ. Na RMBH e na RMSP, tal crescimento foi positivo, mas sempre menor na sede e maior no entorno;

vi. Os domicílios em outra condição de ocupação apresentaram queda em sua participação para todas as regiões. 
Tabela 2 - Condição de ocupação de domićlios, 1991 a 2010, RMs selecionadas

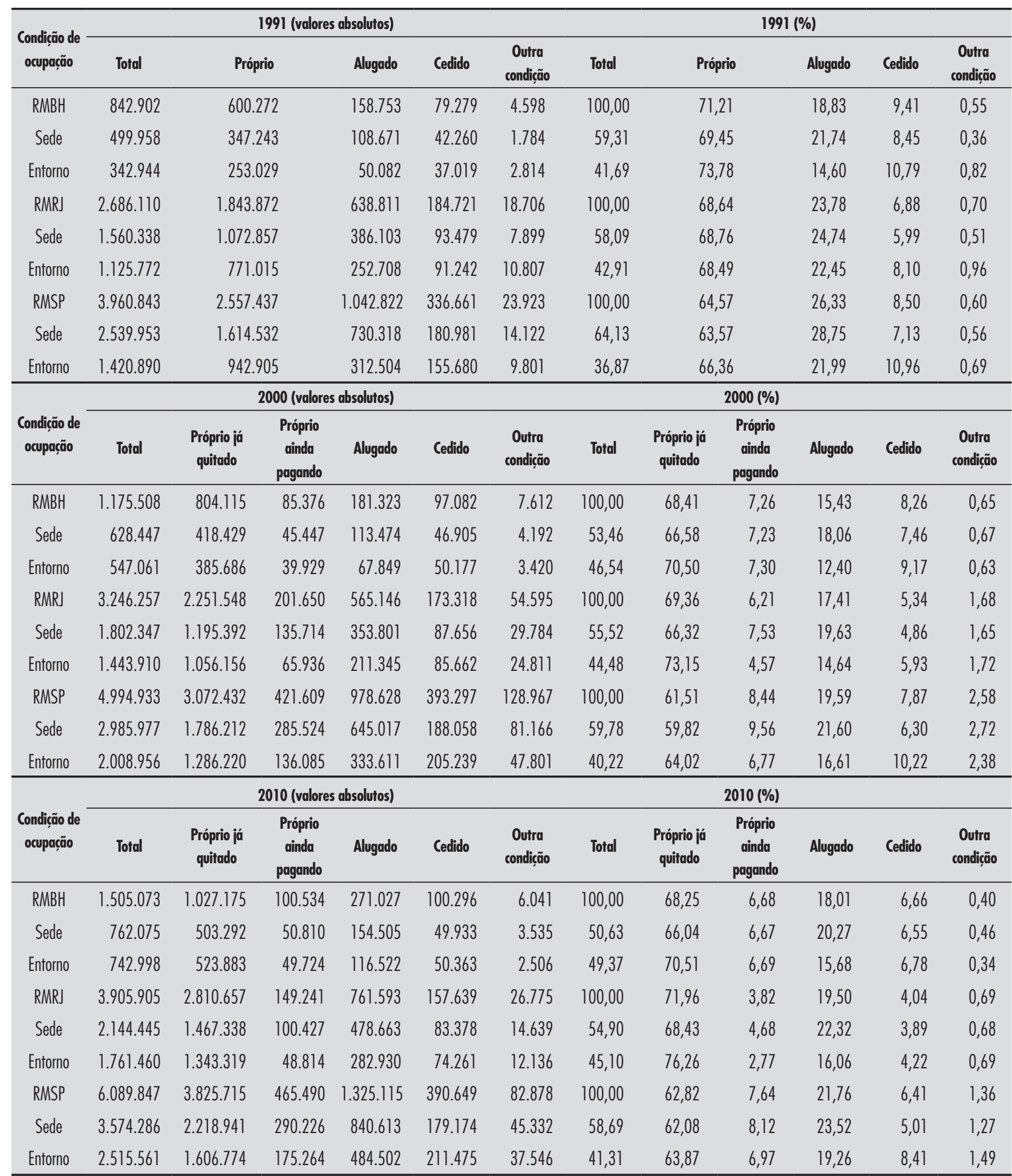

Fonte: Elaborado pelos autores a partir de IBGE (1991, 2000b, 2010b).

Comparando as três metrópoles, verificamos aumento da participação do entorno no período, sendo a sede com maior perda relativo Belo Horizonte, que concentrava 59,31\% dos domicílios em 1991, passando a ter 50,63\% desses em 2010. Nas demais RMs, tal diferença caiu com menor intensidade no período, 
Tabela 3 - População e domićlios nas regiões metropolitanas selecionadas, 1991 a 2010

\begin{tabular}{|c|c|c|c|c|c|c|c|c|c|c|}
\hline & \multirow{2}{*}{ Domicílios } & \multirow{2}{*}{\multicolumn{5}{|c|}{ População }} & \multicolumn{4}{|c|}{ Taxas de crescimento (\% a.a.) } \\
\hline & & & & & & & Popul & ação & Dom & ćlios \\
\hline Ano & 1991 & 2000 & 2010 & 1991 & 2000 & 2010 & $1991 / 2000$ & $2000 / 2010$ & $1991 / 2000$ & $2000 / 2010$ \\
\hline RMBH & 842.902 & 1.175 .508 & 1.505 .073 & 3.522 .908 & 4.357 .942 & 4.883 .970 & 2,39 & 1,15 & 3,76 & 2,50 \\
\hline Sede & 499.958 & 628.447 & 762.075 & 2.020 .161 & 2.238 .526 & 2.375 .151 & 1,15 & 0,59 & 2,57 & 1,95 \\
\hline Entorno & 342.944 & 547.061 & 742.998 & 1.502 .747 & 2.119 .416 & 2.508 .819 & 3,89 & 1,70 & 5,33 & 3,11 \\
\hline RMRJ & 2.686 .110 & 3.246 .257 & 3.905 .905 & 9.796 .649 & 10.869 .255 & 11.835 .708 & 1,16 & 0,86 & 2,13 & 1,87 \\
\hline Sede & 1.560 .338 & 1.802.347 & 2.144 .445 & 5.480 .768 & 5.857 .904 & 6.320 .446 & 0,74 & 0,76 & 1,61 & 1,75 \\
\hline Entorno & 1.125 .772 & 1.443 .910 & 1.761 .460 & 4.315 .881 & 5.011 .351 & 5.515 .262 & 1,67 & 0,96 & 2,80 & 2,01 \\
\hline RMSP & 3.960 .843 & 4.994 .933 & 6.089 .847 & 15.444 .941 & 17.878 .703 & 19.683.975 & 1,64 & 0,97 & 2,61 & 2,00 \\
\hline Sede & 2.539 .953 & 2.985 .977 & 3.574 .286 & 9.646 .185 & 10.434 .252 & 11.253 .503 & 0,88 & 0,76 & 1,81 & 1,81 \\
\hline Entorno & 1.420 .890 & 2.008 .956 & 2.515 .561 & 5.798 .756 & 7.444 .451 & 8.430 .472 & 2,81 & 1,25 & 3,92 & 2,27 \\
\hline
\end{tabular}

Fonte: Elaborado pelos autores a partir de IBGE (1991, 2000b, 2010b).

sendo São Paulo a sede com maior participação entre as três regiões, correspondendo a 58,69\% dos domicílios em 2010.

Seguindo nosso propósito, ressaltamos duas tendências observadas: o aumento da participação dos domicílios alugados entre 2000 e 2010, após a queda entre 1991 e 2000 (queda que foi inclusive em valores absolutos) e a fraca participação dos domicílios em aquisição em 2000, seguida de decréscimo no período intercensitário.

De forma geral, a comparação da dinâmica habitacional entre a sede e o entorno das RMs revela um lado perverso na questão da moradia na primeira década do século XX. Se a década de 1990 foi um período de pouca expansão e integração das políticas nacionais de habitação, a década de 2000 não resultou em avanços significativos, ao menos nas regiões analisadas. Mas há alguma variação em termos espaciais no interior das RMs? Para responder a tais questões, trazemos um conjunto de mapas das regiões, analisando os dados censitários.

0 conjunto de mapas, colocados nas Figuras 1 a 18, denota duas questões acerca de três condições de ocupação: domicílios próprios, alugados e em aquisição. A primeira questão diz respeito às diferentes condições de ocupação do domicílio em relação ao total de domicílios. Tais Figuras ( 1 a 3, 7 a 9,13 a 15) apresentam a razão entre porcentagens de condições de ocupação do domicílio entre 2010 e 2000. Resultados inferiores a 1 indicam que o peso daquele tipo de condição caiu no período, enquanto números superiores a 1 representam o oposto. Com esse quesito, avalia-se a evolução dos pesos relativos de cada uma das variáveis. Já a segunda questão se refere às taxas de crescimento das condições de ocupação, avaliando o crescimento dos níveis absolutos de cada variável (Figuras 4 a 6, 10 a 12, 16 a 18).

De modo geral, em todas as áreas os municípios do entorno apresentaram uma evolução mais intensa dos domicílios, sejam esses próprios, alugados ou em aquisição.

Na RMSP, destacamos a forte queda na cidade de São Paulo do peso dos domicílios em aquisição, com um crescimento próximo a zero. No entorno mais imediato da cidade, essa tendência também é observada. Somente nos municípios mais distantes da sede, como Biritiba-Mirim, Guararema, Franco da Rocha e Cajamar, que não são limítrofes à cidade de São Paulo (ou possuem pontos de contato pouco intensos), houve um crescimento mais significativo de propriedades em aquisição.

Na cidade de São Paulo, os maiores valores estão no crescimento dos domicílios próprios e alugados. Os municípios com maior crescimento das taxas de residências alugadas estão a oeste da cidade de São Paulo.

Em Belo Horizonte também há queda do peso relativo dos domicílios em aquisição no período. $\mathrm{Na}$ cidade, inclusive o total de domicílios próprios 
perde peso. As cidades com as maiores taxas de crescimento estão distantes da sede: Jaboticatubas, Lagoa Santa, Sarzedo, Igarapé, Juatuba e Vespasiano, e somente a última é limítrofe a Belo Horizonte.

Considerando os domicílios em aquisição, os maiores impactos, ou seja, as maiores diferenças positivas entre os pesos relativos dessa categoria, estão novamente em domicílios distantes da sede: Itatiaiuçu, Florestal e Confins são os melhores exemplos. No entanto, há de se observar um crescimento positivo em 1,12\% ao ano dos domicílios em aquisição em Belo Horizonte. Em São Paulo, tal taxa foi de 0,16\%.

Por fim, o Rio de Janeiro foi o caso com o menor índice de crescimento dos domicílios em aquisição entre as três sedes metropolitanas, com uma taxa de $-2,97 \%$ ao ano. Por outro lado, os domicílios no extremo oeste da região metropolitana (Guapimirim, Itaboraí, Tanguá e Maricá) apresentaram as maiores taxas da categoria. É também nessa região que estão as menores taxas entre as três regiões para a categoria: em Nova Iguaçu, houve um crescimento negativo de 8,27\% ao ano no número de unidades em aquisição. Mesmo tendo em mente que o município sofreu um desmembramento recente (com a criação de Mesquita, em 2000), esse é um dado importante. Considerando que essa queda ocorreu pela quitação dos financiamentos já adquiridos nos anos anteriores, que o crescimento total dos domicílios próprios foi também negativo em $0,16 \%$ ao ano, e que a porcentagem de domicílios em aquisição caiu de $5,97 \%$ em 2000 para 2,65\% em 2010, a cidade passa por um momento de crescimento habitacional próximo a zero.

Também é interessante observar o padrão muito próximo entre as dinâmicas da sede (Rio de Janeiro), São Gonçalo e Niterói. As taxas de crescimento e as razões de porcentagens calculadas para as áreas são bastante próximas para as três variáveis.

Como um todo, já era esperado um crescimento do entorno maior do que o verificado nas sedes das três RMs. Essas já estão mais consolidadas, com menor margem para o crescimento populacional e habitacional. No entanto, não verificamos tendências de mudanças na estrutura habitacional das regiões, com diversas situações em que o peso das unidades financiadas é baixo e seu crescimento negativo.

As consequências desse processo são muitas. Em termos sociodemográficos, uma questão notória

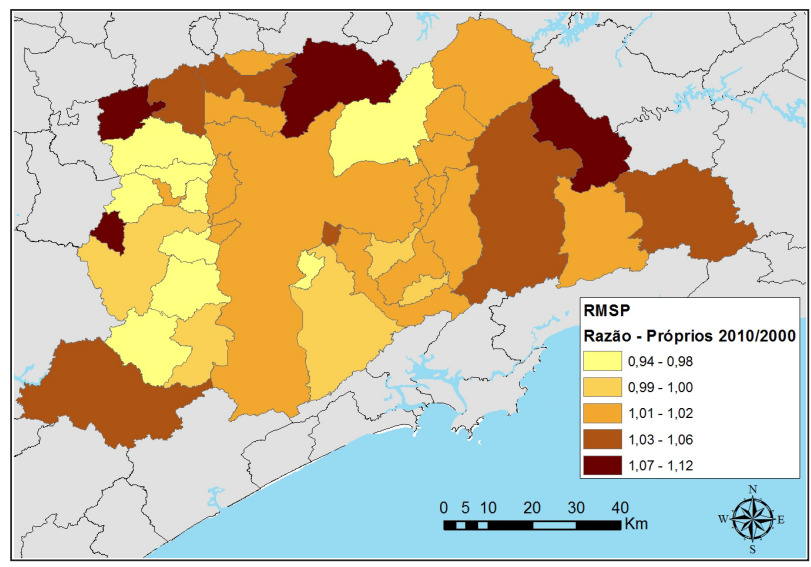

Figura 1 - Razão entre as porcentagens de domićlios próprios em 2010 e 2000, RMSP Fonte: IBGE (2000a, 2000b, 2010a, 2010b).

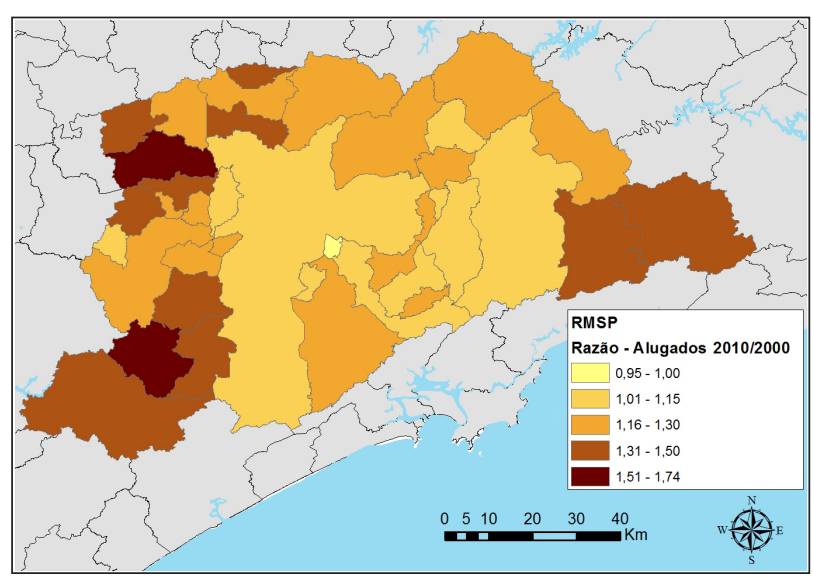

Figura 2 - Raz̃̃o entre as porcentagens de domiclilios alugados em 2010 e 2000, RMSP Fonte: IBGE (2000a, 2000b, 2010a, 2010b).

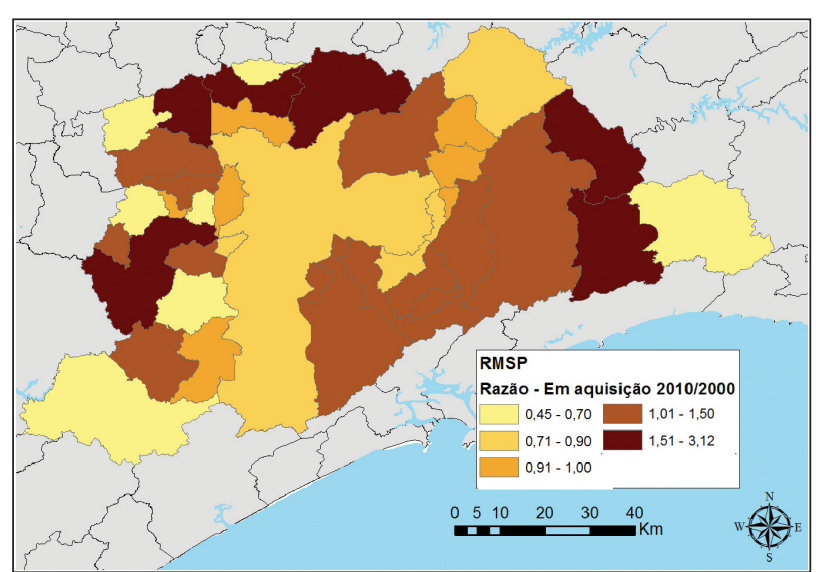

Figura 3-Raz̃o entre as porcentagens de domiclilios em aquisicĩãoem 2010 e 2000, RMSP Fonte: IBGE (2000a, 2000b, 2010a, 2010b). 


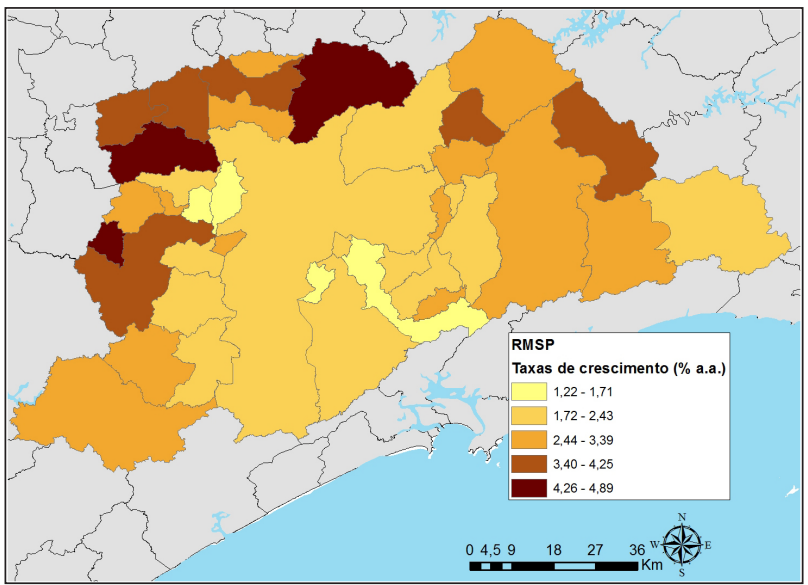

Figura 4 - Taxas de crescimento de domićlios próprios $2000-2010$ (\% a.a.), RMSP Fonte: IBGE (2000a, 2000b, 2010a, 2010b).

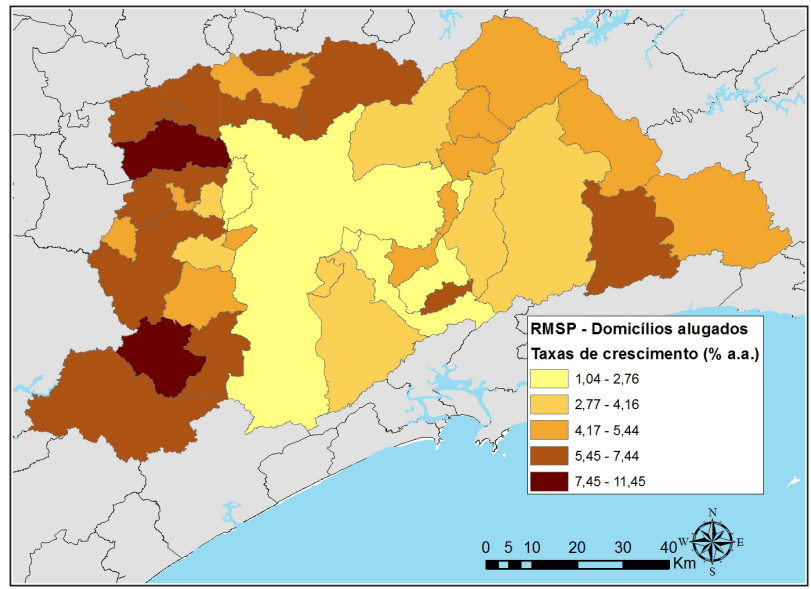

Figura 5 - Taxas de crescimento de domićlios alugados $2000-2010$ (\% a.a.), RMSP Fonte: IBGE (2000a, 2000b, 2010a, 2010b).

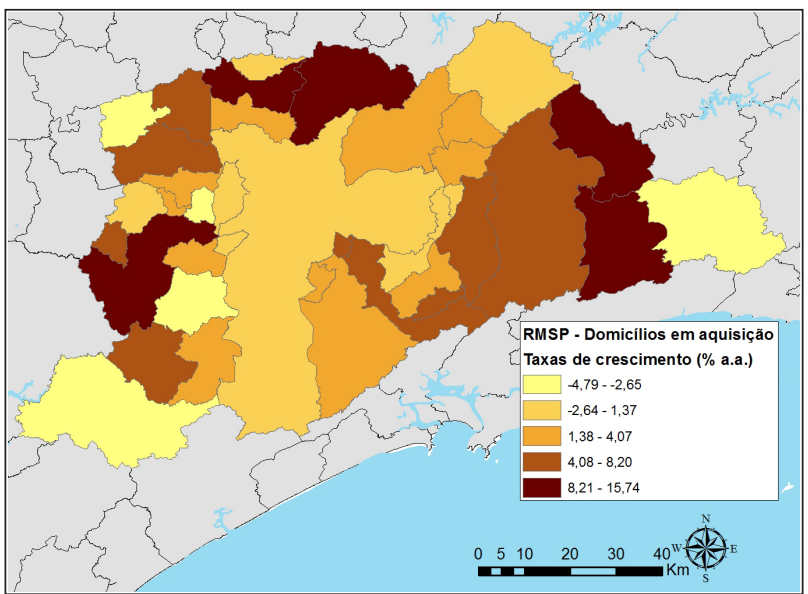

Figura 6 - Taxas de crescimento de domiclilios em aquisiç̃̃o $2000-2010$ (\% a.a.), RMSP Fonte: IBGE (2000a, 2000b, 2010a, 2010b).

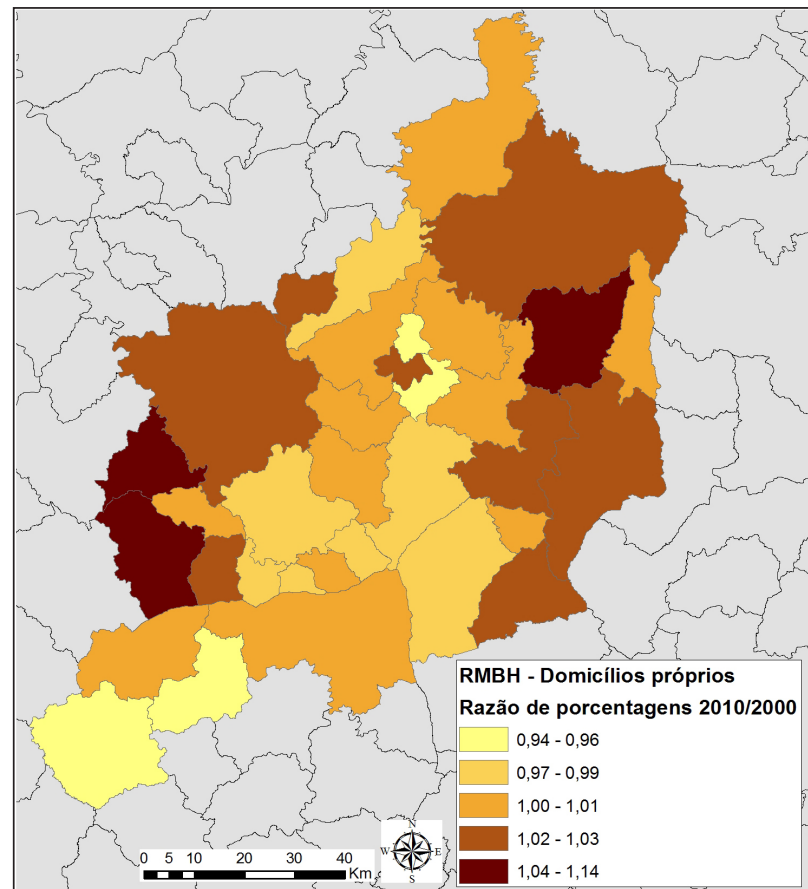

Figura 7 - Raz̃̃o entre as porcentagens de domićlios próprios em 2010 e 2000, RMBH Fonte: IBGE (2000a, 2000b, 2010a, 2010b).

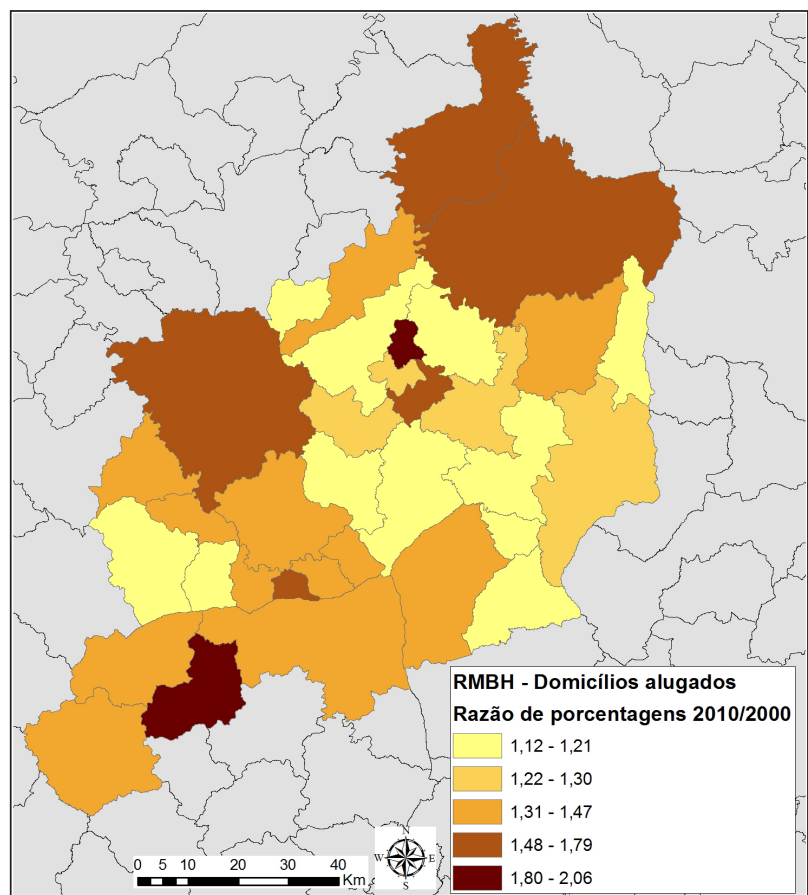

Figura 8 - Razão entre as porcentagens de domićlilos alugados em 2010 e 2000, RMBH Fonte: IBGE (2000a, 2000b, 2010a, 2010b). 


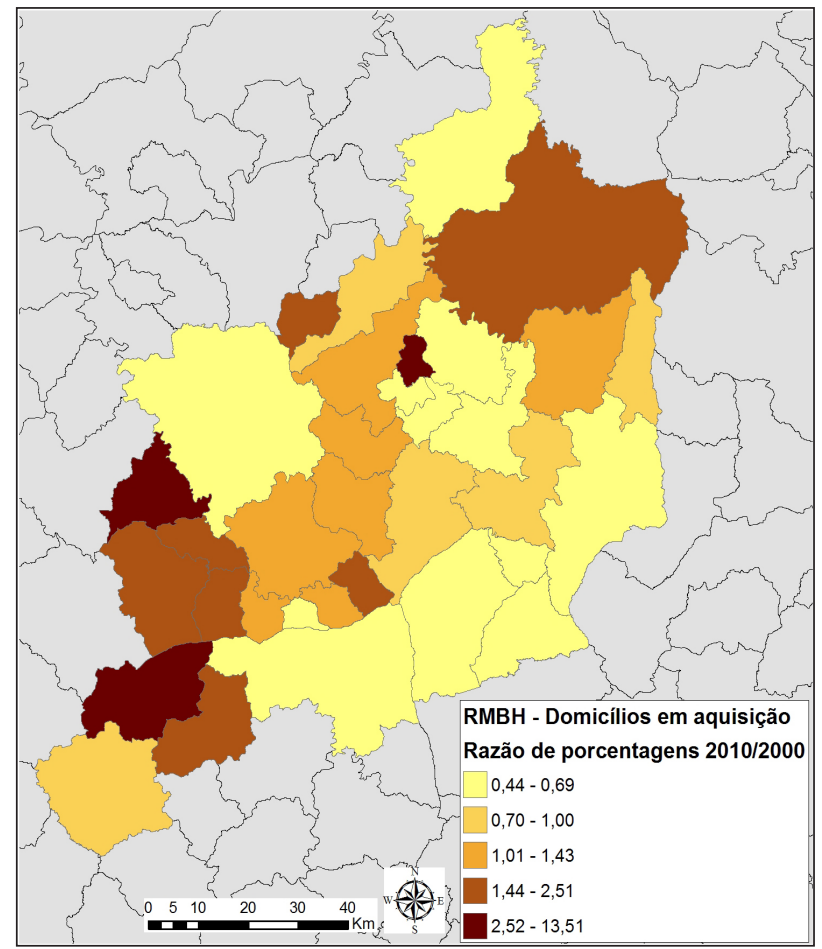

Figura 9-Razão entre as porcentagens de domićlíios em aquisiç̃̃o em 2010 e 2000, RMBH Fonte: IBGE (2000a, 2000b, 2010a, 2010b).

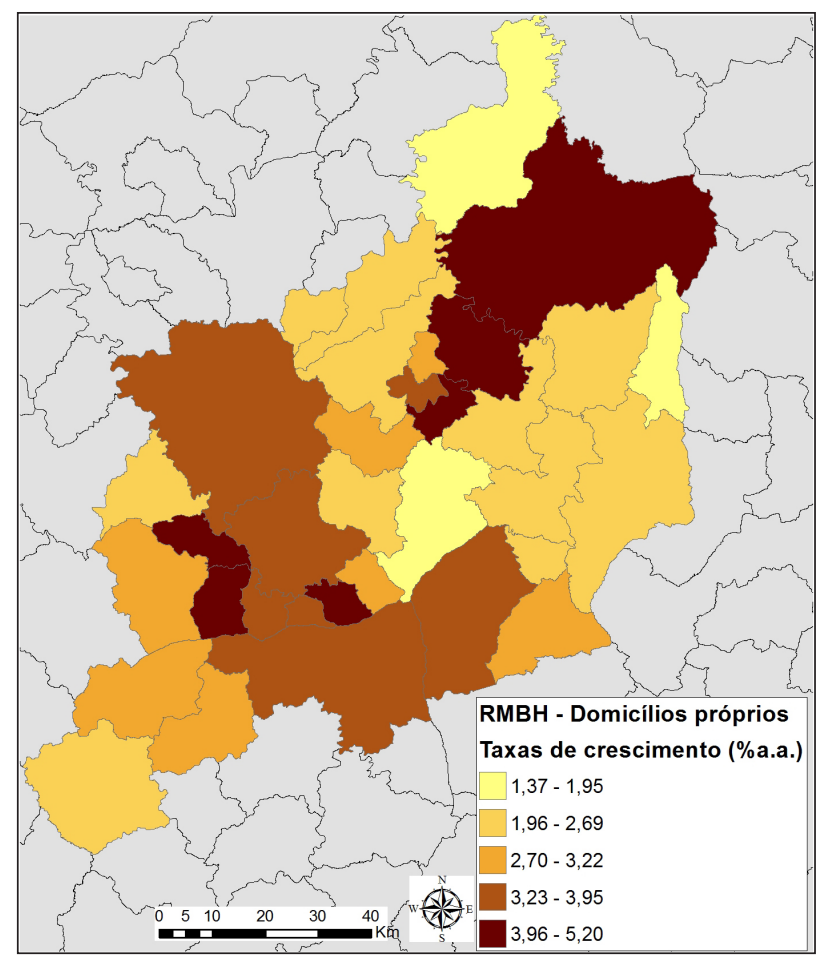

Figura 10 - Taxas de crescimento de domićlios próprios 2000-2010 (\% a.a.), RMBH Fonte: IBGE (2000a, 2000b, 2010a, 2010b).

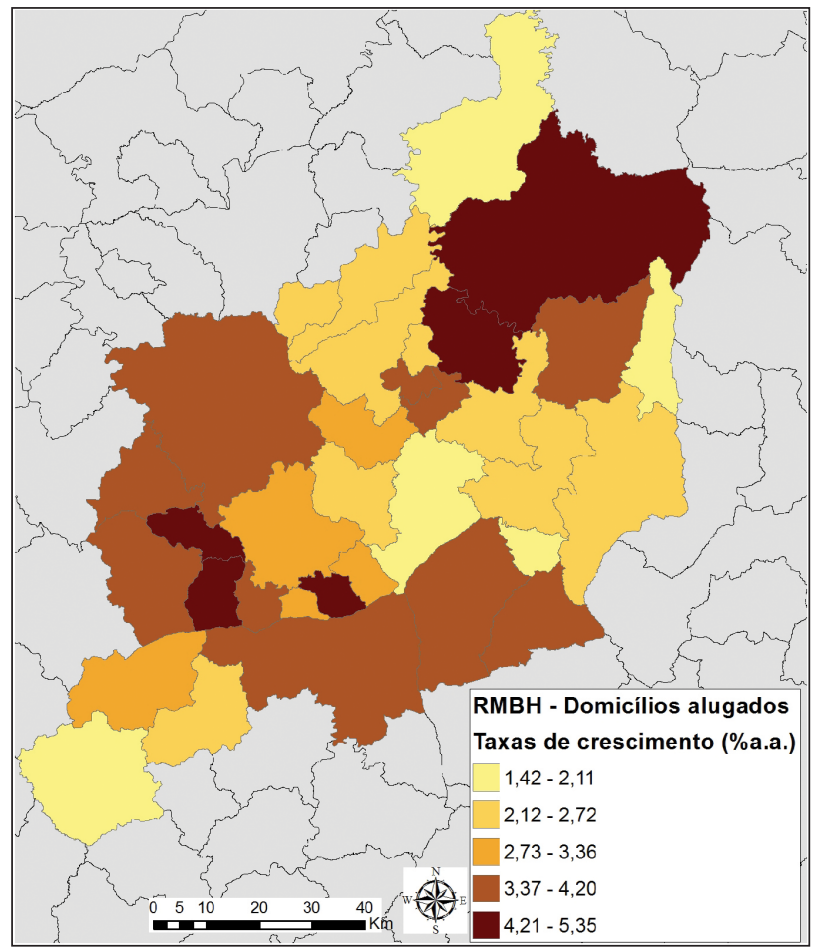

Figura 11 - Taxas de crescimento de domićlios alugados 2000-2010 (\% a.a.), RMBH Fonte: IBGE (2000a, 2000b, 2010a, 2010b).

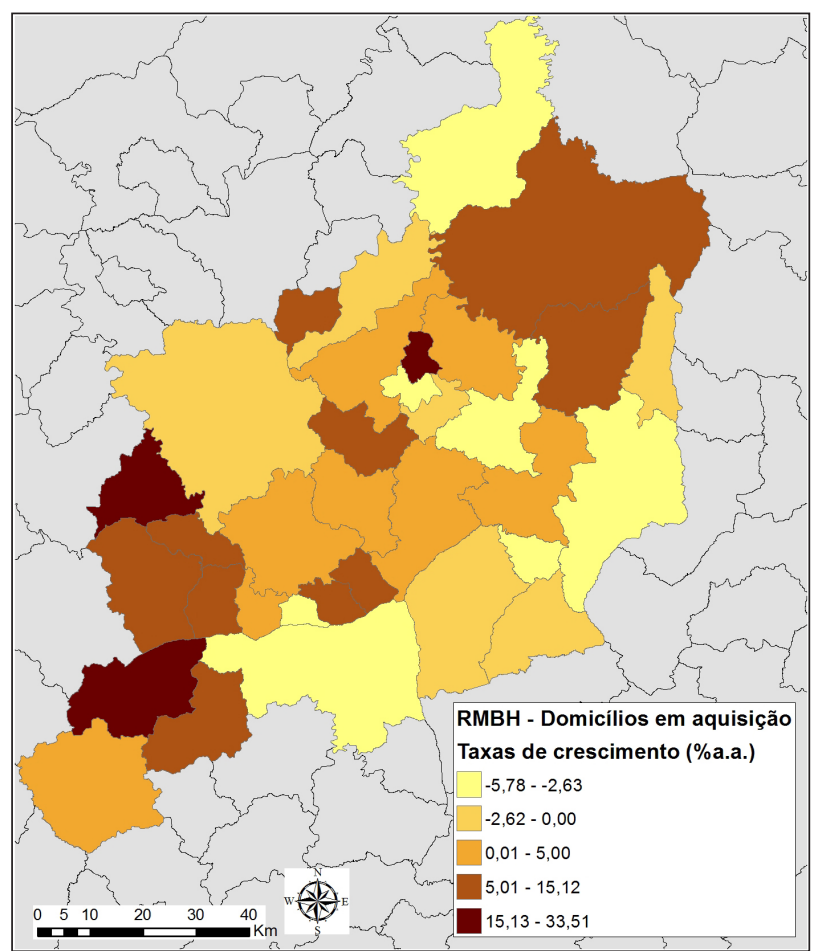

Figura 12 - Taxas de crescimento de domićlíios em aquisiç̃o 2000-2010 (\% a.a.), RMBH Fonte: IBGE (2000a, 2000b, 2010a, 2010b). 


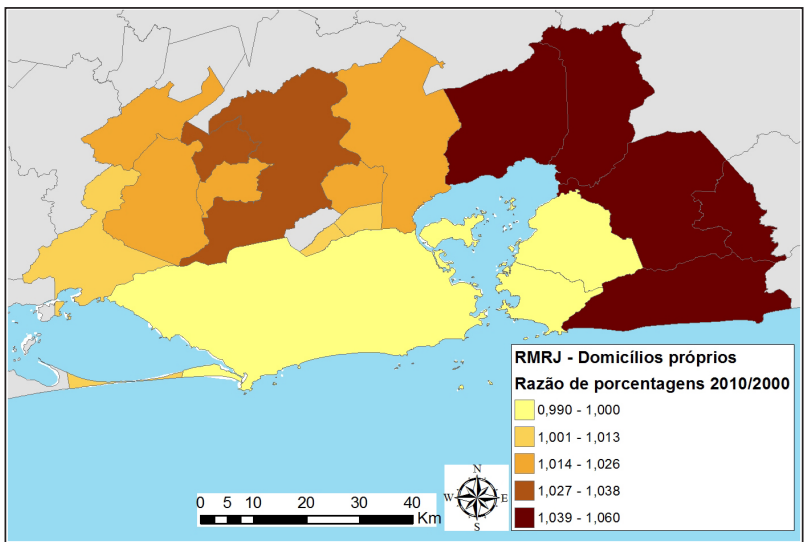

Figura 13 - Razõo entre as porcentagens de domićlios próprios em 2010 e 2000, RMRJ Fonte: IBGE (2000a, 2000b, 2010a, 2010b).

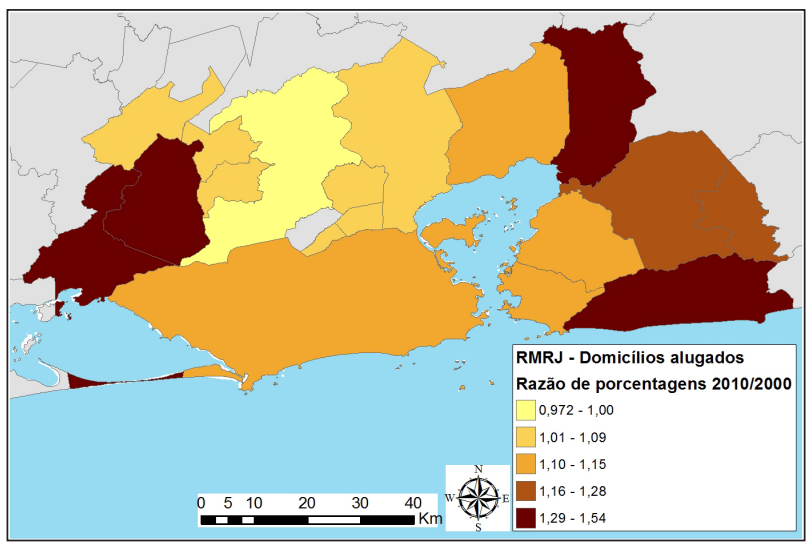

Figura 14 - Razão entre as porcentagens de domićlios alugados em 2010 e 2000, RMRJ Fonte: IBGE (2000a, 2000b, 2010a, 2010b).

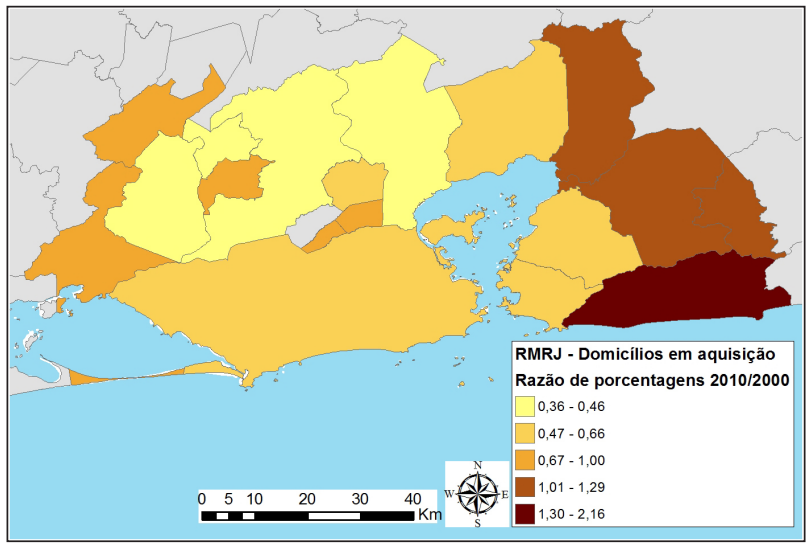

Figura 15 -Razz̃o entreas porcentagensdedomicliliosem aquisiçãoem 2010e 2000, RMRJ Fonte: IBGE (2000a, 2000b, 2010a, 2010b).

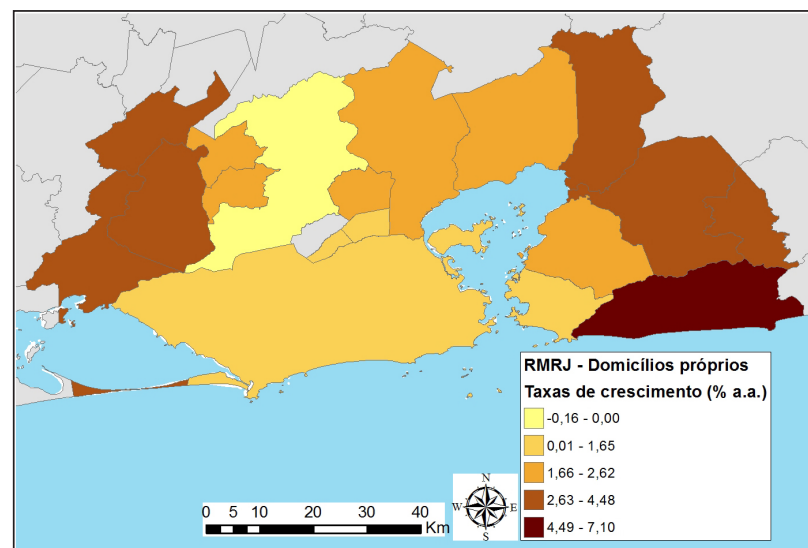

Figura 16 - Taxas de crescimento de domićlios próprios $2000-2010$ (\% a.a.), RMRJ Fonte: IBGE (2000a, 2000b, 2010a, 2010b).

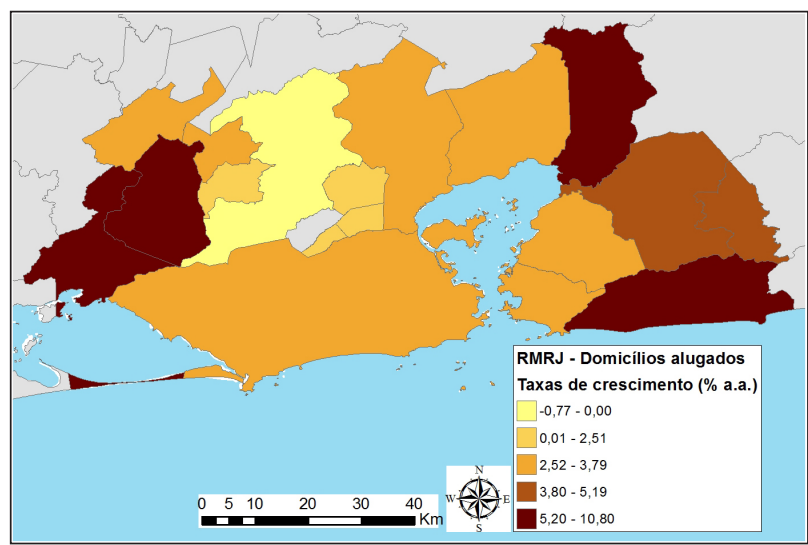

Figura 17 - Taxas de crescimento de domićlios alugados $2000-2010$ (\% a.a.), RMRJ Fonte: IBGE (2000a, 2000b, 2010a, 2010b).

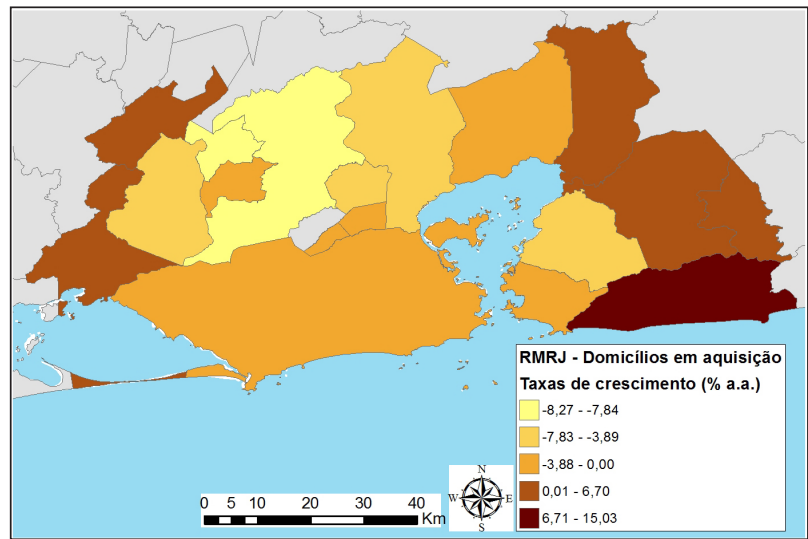

Figura 18 - Taxas de crescimento de domicilios em aquisiçã̃o $2000-2010$ (\% a.a.). RMRJ Fonte: IBGE (2000a, 2000b, 2010a, 2010b). 
diz respeito à mobilidade e aos deslocamentos cotidianos. Já na década de 1970, o longo dispêndio de tempo gasto para se chegar ao trabalho a partir das distantes periferias já se configurava como uma questão importante para os moradores metropolitanos. Como tal movimento ocorre na atualidade? Há diferença para os habitantes da sede metropolitana e de seu entorno? A partir do Censo Demográfico 2010, é possível observar o local de moradia e o tempo médio gasto no deslocamento, conforme revela o Gráfico 1.
De modo geral, a maior parte dos moradores das sedes trabalham no próprio município. Fixar moradia na sede aumenta significativamente as chances de trabalhar no mesmo município. Embora tenham apresentado diferenças percentuais muito próximas, a menor diferença entre as áreas foi na $\mathrm{RMBH}$, e a maior foi na RMRJ. Foi na última também que se concentrou a menor porcentagem de populações que vivem no entorno da sede da RM e que trabalham no mesmo município de residência, com 59,88\%. No entanto, nas demais áreas essa porcentagem

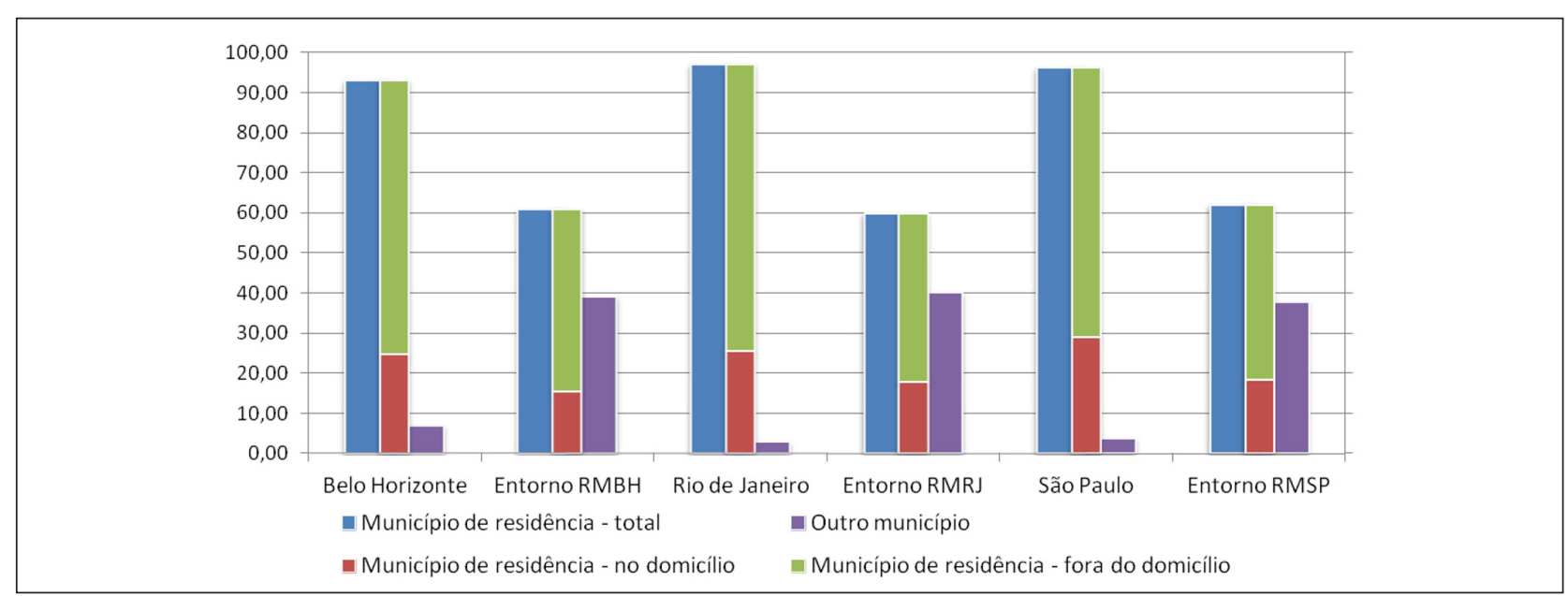

Gráfico 1 - População ocupada (\%) por local de trabalho, áreas selecionadas, 2010 Fonte: Elaborado pelos autores a partir de IBGE (2010b).

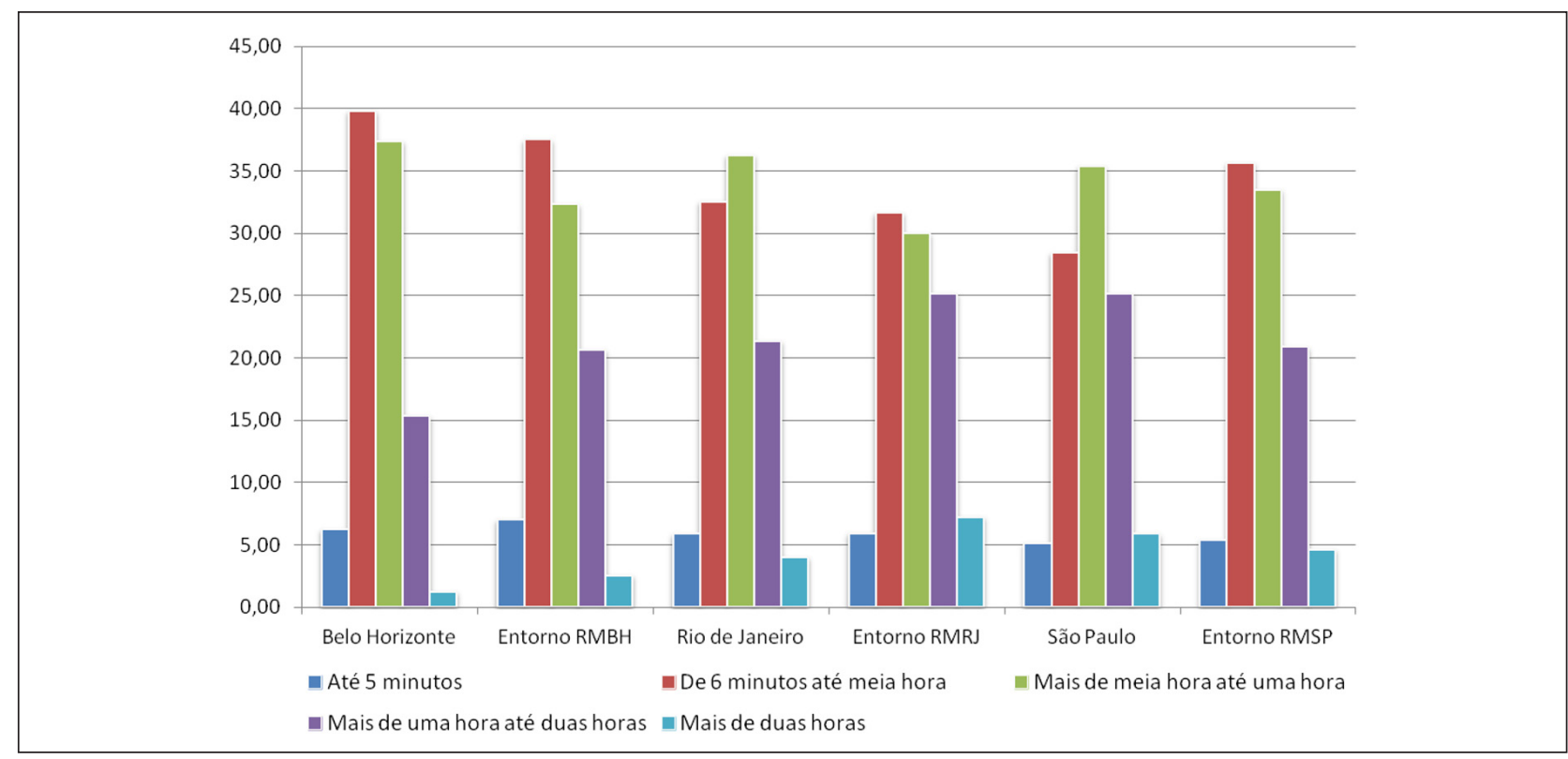

Gráfico 2 - Tempo de deslocamento casa-trabalho por áreas selecionadas, 2010 Fonte: Elaborado pelos autores a partir de IBGE (2010b). 
foi muito próxima de $60,94 \%$ na RMBH e $62,09 \%$ na RMSP.

Se os moradores da sede trabalham no mesmo município, será que isso também implica tempos menores de deslocamento ao trabalho? 0 Gráfico 2 indica que o resultado será variado entre as RMs. Na RMBH e na RMRJ, os grupos que gastam um tempo menor no deslocamento casa-trabalho (de até 30 minutos) estão concentrados na sede. No entorno cresce significativamente a porcentagem de pessoas que gastam mais de uma hora para chegar ao trabalho. Ganha destaque um grupo que demora mais de 2 horas nesse deslocamento, no entorno do Rio de Janeiro. São 211.971 pessoas, 7,23\% da população ocupada, que gasta mais de 4 horas diárias no trajeto casa-trabalho-casa.

Já em São Paulo, as questões se invertem. Morar na sede não significa despender um tempo menor até o trabalho, mas sim o contrário. As categorias com menor tempo representam um grupo maior no entorno do que na sede. Consequentemente, em São Paulo é relativamente alto o grupo que gasta mais de uma hora para chegar ao trabalho. Pouco mais de $30 \%$ dos trabalhadores fazem parte desse grupo, e desses, $20 \%$ despendem ao menos 4 horas diárias nesse deslocamento.

De certo modo, essa dinâmica reflete a própria diversidade de grandes centros e metrópoles. Morar na sede não significa ter boa qualidade de vida ou condições dignas de moradia. Tais centros são extremamente desiguais e agregam as mais diferentes classes sociais. Para apreender melhor essa dimensão do habitar, são necessárias pesquisas que também analisem a relação domicílio, mobilidade e trabalho em função de outros atributos, como classes de renda, local de trabalho, setor de empregabilidade e educação, dentre outros.

\section{Considerações finais}

Os aclamados programas habitacionais lançados no Brasil recentemente parecem ainda não ter atingido os efeitos esperados. Ao menos até aqui, partindo das análises dos dados dos Censos Demográficos, as perspectivas não são animadoras. Os melhores resultados, indicando um crescimento das residências em aquisição, estão em áreas distantes das sedes, que possuem um grande contingente de pessoas trabalhando em outros municípios e levando um tempo bastante alto na mobilidade cotidiana.

Por outro lado, os números da construção civil nessa década foram surpreendentes. 0 crescimento total dos domicílios foi bastante elevado e superior ao crescimento da população. Nesse cenário, houve aquecimento do mercado imobiliário, com um aumento do preço das construções e do solo urbano que inviabiliza a compra de imóveis dignos e em locais adequados pela maior parte da população. Será esse um dos, senão o maior efeito da retomada dos financiamentos e da política habitacional no Brasil durante a década de 2000? Considerando a estabilidade dos números absolutos do déficit habitacional, a resposta parece ser positiva.

Desse modo, é preciso compreender se seria necessária a construção de novas unidades para todos os demandantes, já que frequentemente essa é vista como a solução para o déficit habitacional. No entanto, a PNAD de 2008 indica que o Brasil possuía, naquele ano, 7,542 milhões de imóveis vagos, dos quais 6,307 milhões estariam em condições de serem ocupados, 894 mil em construção ou reforma e 340 mil em ruínas. Grande parte desse número é o estoque de mercado, destinado a uma camada da população com perfil bastante diferente daquele que demanda moradias (Brasil, 2011). Mas tal característica poderia ser incorporada na resolução dos problemas habitacionais? Grande parte das áreas centrais das grandes cidades estão degradadas e, quando recuperadas, corre-se o risco de serem apropriadas somente pelas classes de maior poder. A habitação é o grande desafio da recuperação, já que geralmente os modelos são feitos a partir da revitalização dos serviços e incentivos à cultura, favorecendo a expulsão da população de baixa renda ${ }^{4}$. Dois dos projetos mais controversos nesse âmbito são o da "Nova Luz", em São Paulo, e da revitalização da área portuária, no Rio de Janeiro ${ }^{5}$.

\footnotetext{
4 Para mais informações ver http://www.revistaau.com.br/ arquitetura-urbanismo/197/o-futuro-aponta-para-o-centro-181294-1.asp.

5 Para mais informações ver http://www.spressosp.com. br/2012/02/ativista-diz-que-especulacao-imobiliaria-eum-\%E2\%80\%9Ccancer-na-sociedade $\%$ E2\%80\%9D/ e http://www.projetobrasil2 014.com.br/wp-content/uploads/2011/06/Livro10_brasil2014.pdf.
} 
Em ambos, a questão primordial se refere ao tipo de intervenção estatal e os principais beneficiados. Quais grupos sociais e quais usos residenciais serão efetivados após a revitalização?

A política habitacional brasileira parece continuar sem grandes rupturas, tratando o solo urbano sem considerar os efeitos na especulação imobiliária e das desigualdades socioterritoriais. Talvez os maiores impactos de programas como o PMCMV ainda sejam sentidos nos próximos anos, já que esse ainda é muito recente. Por outro lado, as constatações indicam que ele é insuficiente. Além da demora na finalização do processo de construção e entrega das unidades, ao menos por enquanto é mínima a parcela de imóveis destinados às populações com menor renda, justamente com quem se dá a maior dívida histórico-urbana do país ${ }^{6}$.

\section{Referências}

Alcântara, F. G., Fo. (2009). Evolução de preços imobiliários nas diferentes regiões da cidade de São Paulo (Dissertação de mestrado). Escola de Administração de Empresas de São Paulo, São Paulo.

Bonduki, N. (2008). Política habitacional e inclusão social no Brasil: revisão histórica e novas perspectivas no governo Lula. Revista Eletrônica de Arquitetura e Urbanismo, (1), 71-104.

Bonduki, N. G., \& Rolnik, R. (1978). Periferias: ocupação do espaço e reprodução da força de trabalho. São Paulo: EDUSP.

Brasil. (1986). Decreto Lei no 2.291 de 21 de Novembro de 1986. Extingue o Banco Nacional da Habitação - BNH, e dá outras Providências. Brasília: Diário Oficial da União.

Brasil. (1988). Constituição da República Federativa do Brasil de 1988. Brasília.

Brasil. Ministério das Cidades. Secretaria Nacional de Habitação. (2011). Déficit habitacional no Brasil 2008. Fundação João Pinheiro, Centro de Estatística e Informações.

6 Estimativas do desempenho do programa podem ser acessadas em http://apeop.org.br/noticia/habitacao-934/ minha-casa-minha-vida-2-so-entrega-2-das-casas-parabaixa-renda- 624 .
Bratt, R. G., Stoney, M. E., \& Hartman, C. (2006). A right to housing: foundation for a new social agenda. Filadelfia: Temple University Press.

Caixa Econômica Federal - CEF. (2011). Demanda habitacional no Brasil. Brasília.

Carvalho, S. N. (2011). Cidades e políticas de habitação. In R. Baeninger (Org.), População e cidades: subsídios para o planejamento e para as políticas sociais. Campinas: NEPOUNICAMP; Brasília: UNFPA.

Cepal. (2006). Instrumentos financieros para mejorar el acceso a la vivienda de los sectores de menores ingresos en América Latina y el Caribe. In XV Asamblea General de Ministros y Autoridades Máximas de la Vivienda y el Urbanismo de América Latina y el Caribe, Minurvi. Recuperado em 09 de julho de 2012, de http://www. minurvi.org/documentos/2_Asambleas/Instrumentos\%20 financieros\%20octubre\%2010.pdf

Cuaresma, J. C. (2010). Can emerging asset price bubbles be detected? Organisation for economic co-operation and development (ECO Working Papers, No. 28). OECD.

Czischke, D., \& Pittini, A. (2007). Housing Europe 2007: review of social, Co-operative and Public Housing in the 27 EU Member States. Brussels: CECODHAS European Social Housing Observatory.

D’Agostini, L. L. M. (2010). A bolha imobiliária no Brasil está formada. Economia \& Tecnologia, 23, 41-52.

Dezordi, L. L. (2012). Perspectivas para o desempenho nos preços dos apartamentos de 1 a 4 dormitórios em Curitiba: junho de 2012. Recuperado em julho de 2012, de http:// www.corecon-pr.org.br/v2009/images/stories/doc/ estudo1.pdf

Dodson, J. (2006). Rolling the State? Government, neoliberalism and housing assistance in four advanced economies. (Urban Research Program: Research Paper, No. 7). Griffith University. Recuperado em 09 de julho de 2012, de http:// www.griffith.edu.au/_data/assets/pdf_file/0003/48576/ urp-rp07-dodson-2006.pdf

Faria, V. (1991). Cinquenta anos de urbanização no Brasil: tendências e perspectivas. Novos Estudos CEBRAP, (29), 98-119.

Fernandes, C. C. P., \& Silveira, S. F. R. (2010). Ações e contexto da política nacional de habitação: da Fundação Casa Popular ao Programa "Minha Casa, Minha Vida". In Anais do II Encontro Mineiro de Administração Pública, Economia Solidária e Gestão Pública (p. 8-21). Viçosa: UFV. 
Garcia, F., \& Castelo, A. M. (2006). O déficit habitacional cresce apesar da ampliação do crédito. Conjuntura da Construção, 4(1), 8-11.

Instituto Brasileiro de Geografia e Estatística - IBGE (1991). Censo demográfico 1991. Rio de Janeiro.

Instituto Brasileiro de Geografia e Estatística - IBGE. (2000a). Malha de setores censitários 2000. Rio de Janeiro.

Instituto Brasileiro de Geografia e Estatística - IBGE. (2000b). Censo demográfico 2000. Rio de Janeiro.

Instituto Brasileiro de Geografia e Estatística - IBGE. (2010a). Malha de setores censitários 2010. Rio de Janeiro.

Instituto Brasileiro de Geografia e Estatística - IBGE. (2010b). Censo Demográfico 2010. Rio de Janeiro.

Köhler, M. A. (2005). Financiamento habitacional. Brasília: Consultoria Legislativa do Senado Federal.

Kowarick, L. (1993). A espoliação urbana (2a ed.). Rio de Janeiro: Paz e Terra.

Maricato, E. (1979). A produção social da casa e da cidade no Brasil industrial. São Paulo: Alfa-ômega.

Maricato, E. (2011). Metrópoles desgovernadas. Estudos Avançados, 25(71), 7-22.

Martine, G., \& Camargo, L. (1984). Crescimento e distribuição da população brasileira: tendências recentes. Revista Brasileira de Estudos Populacionais, 1(1-2), 99-143.
Morais, M. P. (2002). Breve diagnóstico sobre o quadro atual da habitação no Brasil. Boletim de Políticas Sociais @Acompanhamento e Análise. (4).

ONU-HABITAT. (2010). Estado de las Ciudades de América Latina y el Caribe. Rio de Janeiro.

Rolnik, R. (2009). Financial crisis and the right to adequate housing. Relatório Temático Apresentado à Assembleia Geral da ONU. Recuperado em 09 de julho de 2012, de http:// direitoamoradia.org/?page_id=1144\&lang=pt

Rolnik, R., \& Klink, J. J. (2011). Crescimento econômico e desenvolvimento urbano: por que nossas cidades continuam tão precárias? Novos Estudos CEBRAP, 89(89), 89-109. http://dx.doi.org/10.1590/S0101-33002011000100006

Royer, L. O. (2009). Financeirização da política habitacional: limites e perspectivas (Tese de doutorado). Faculdade de Arquitetura e Urbanismo, Universidade de São Paulo.

Singer, P. (1974). Implicações econômicas e sociais da dinâmica populacional brasileira. Estudos Sobre a População Brasileira: Caderno CEBRAP, 20, 5-16.

Yoshimura, M. T. (2004). Análise das tendências de financiamento público para habitação social: o caso de Jaboticabal/SP (Dissertação de Mestrado em Engenharia Urbana). Universidade Federal de São Carlos, São Paulo.

Recebido: Ago. 08, 2014

Aprovado: Nov. 10, 2014 